\title{
Progression of Charcot-Marie-Tooth Foot and Hand Deformities in a Family with CMT1A
}

Kristyn Pocock MD $\mathrm{MD}^{1}$ and Tuan H. Vu MD²

${ }^{1}$ Swedish Neuroscience Institute, Seattle, WA

${ }^{2}$ University of South Florida, Tampa, FL

Keywords: Charcot-Marie-Tooth, Hereditary Neuropathy, Neuropathy, Pes Cavus.

\section{Case Summary}

A 6-year-old girl presented to our clinic with her mother and grandmother to establish care for Charcot-Marie-Tooth Type 1A (CMT1A), an autosomal dominantly inherited sensorimotor neuropathy due to PMP22 duplication. The progression of pes cavus, characterized by the increasing plantar concavity over time, and hammertoe deformities, due to the insidious atrophy of the intrinsic foot musculature, are observed in this family. ${ }^{1}$ In addition to pedal deformities, our patient has ankle dorsiflexion weakness, requiring bilateral ankle-foot orthoses. Distal weakness and pes cavus deformity are the most common initial signs of CMTlA.

Corresponding author: Kristyn Pocock

Kristyn.pocock@swedish.org

\section{References}

${ }^{1}$ Amato, Anthony A., and James A. Russell. Neuromuscular disorders. McGraw Hill Professional, 2015.
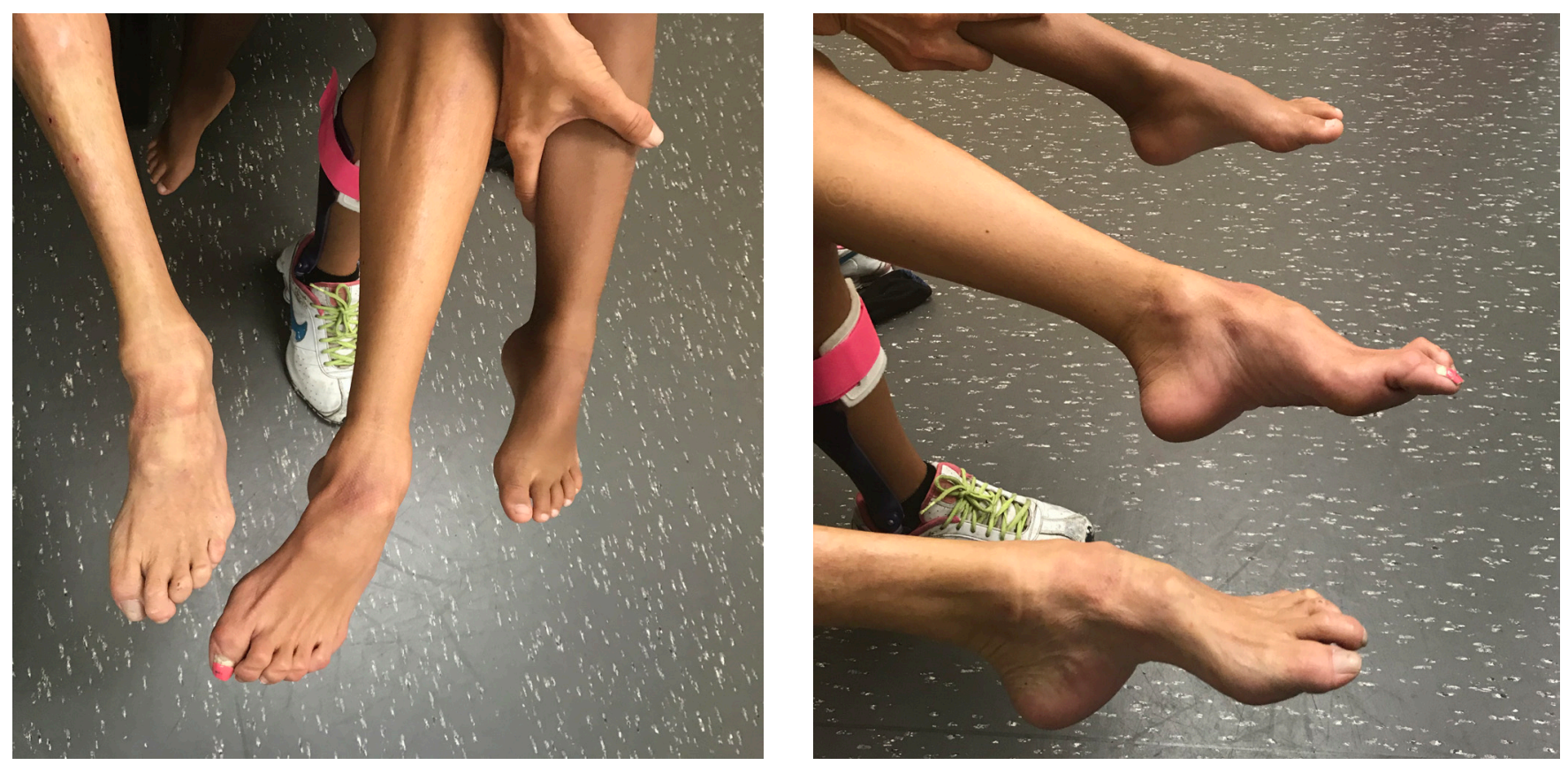

\section{Figure 1 Legend}

Progression of foot deformities in a family with CMT1A. A. The patient's feet (top) shows the onset of pes cavus and hammertoes, which become progressively more prominent in her 29-year-old mother (middle) and 50-year-old grandmother (bottom). B. The grandmother also has distal leg atrophy, resulting in stork-leg (or inverted champagne bottle) appearance. 

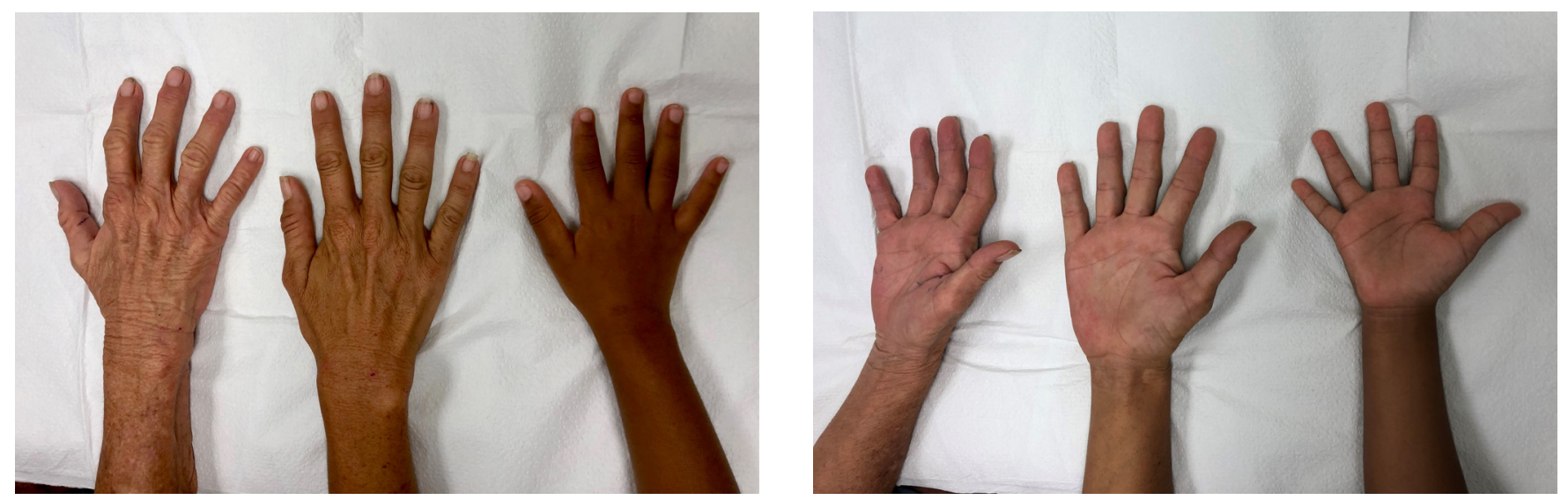

\section{Figure $\mathbf{2}$ Legend}

Progression of hand deformities in the same family. The patient's hand (top) demonstrates preserved intrinsic hand muscle bulk. Over time, there is loss of the dorsal interossei and lumbrical muscles in her mother (middle) and grandmother (bottom). 